\title{
AUTOMATIC POWER GENERATION CONTROL STRUCTURE FOR SMART ELECTRICAL POWER GRIDS
}

\author{
G.B.Hangargi ${ }^{1}$ \\ ${ }^{I}$ Associate Professor, Electronics and communication Enggdept, BheemannaKhandreInstitute of Technology Bhalki, \\ Karnataka
}

\begin{abstract}
Smart electrical power grids with high saturation of intermittent, non dispatchable distributed energy resources (ING), and virtual networks with real-time rating for a new tools for automatic electrical power generation with control (A EPGC) structure. The main drawback of the intermittency are higher use of expensive spinning reserves, usually gas-fired units, nonrenewable sources units and thermal units because of variation of turbine valves of steam units and hydro units for load regulation system. This paper presents a new AEPGC structure to overcome the drawback of intermittency in electrical smart power grids. The constant pressure steam (CPS), thermal units and nuclear system of variable pressure steam (VPS) are controlled to low and high frequencies load dynamic based responses on a one-step head in advance load target. The distribution community storage (DCS) together with load dynamic response $(D R)$ and aggregate $D R$ as virtual generator $(D R / V G)$ assets are used to control high-frequency load fluctuations. The INGs and nuclear units are used as base loads system.
\end{abstract}

Keywords: Automatic electrical power generation control, Cyber virtual network, Intermittent, renewable, non renewable, smart power grids system.

\section{INTRODUCTION}

There port on annual bases of energy system [1] It observed that up to by 2040, the combined intermittent, non dispatchable ING sources are expected to deliver more than $5 \%$ of total generation in electric power(energy). Impediments to increasing this percentage of electric power from (i) to install costly spinning-reserves needs (ii) for load control purposed the wear and tear of thermal and gas fired units are used and (iii) carbon track of nonrenewable units are used. The author (I) submit that by the use of a grid-pervasive installation of distributed community storage (DCS) and demand response/virtual generator (DR/VG) units, both in utility substations and micro grids and automatic monitored by independent system operator (ISO), automatic electrical power generation control (AEPGC) will have the needed assets to control the intermittency of INGs. In the proposed AEPGC structure, AEPGC controls variable pressure steam (VPS), constant pressure steam (CPS) units used for low frequency load fluctuations proposed, DCS and DR/VG assets effectively control the high frequency load variations this paper (I) addresses the following:

1. Current AEPGC software and with its drawbacks.

2 .A new AEPGC and virtual cyber architecture to used in the place of the intermittency of INGs

3 One-step-ahead on load forecast (Future load) for valve point can be controlled by a CPS assets.

4 DCS and (VGs) are to control intermittency of intermittent, non dispatch able distributed energy resources (INGs).
5 Optimal dynamic load controls of VPS units to follow a onestep-ahead load goal.

\section{AUTOMATICPOWER GENERATION CONTROL SYSTEM}

The objectives of automatic power generation control (AEPGC) are as follows:

i) Matching of electrical power generation system to the power consumed area load. It means that matching control of the system frequency to the tie-line system frequency interchanged with the time period.

ii)for security consideration [2]-[6] the changing the distributing loads among generators so as to reduced the operating costs subject

The first objective is met additional purposed controller in which the concept of tie-line bias is permanently used for a small change in the system load frequency produces directly changes in the system frequency. The area control error is given by

$$
A C E=\Delta P_{T L}-\beta \Delta f
$$

In this case each area with fairly accurate knowledge of the load changes and directs the additional controller for the area to small changes of the turbine values of steam units as well as to 
reduce ACE to zero valves. Through ACE control, the load demands of the grid are observing every few seconds.

The second objective is met by observing the load every few minutes (i.e.5-10 min) and as long as the changing load system among different units for to lowest cost of the operation based on economic dispatch calculation (EDC). During in this period, the load demand remains constant of EDC. Fig. 2 shows that ACE of an ISO with a sampling of ACE to an ISO with a sampling rate of $5 \mathrm{~s}$.

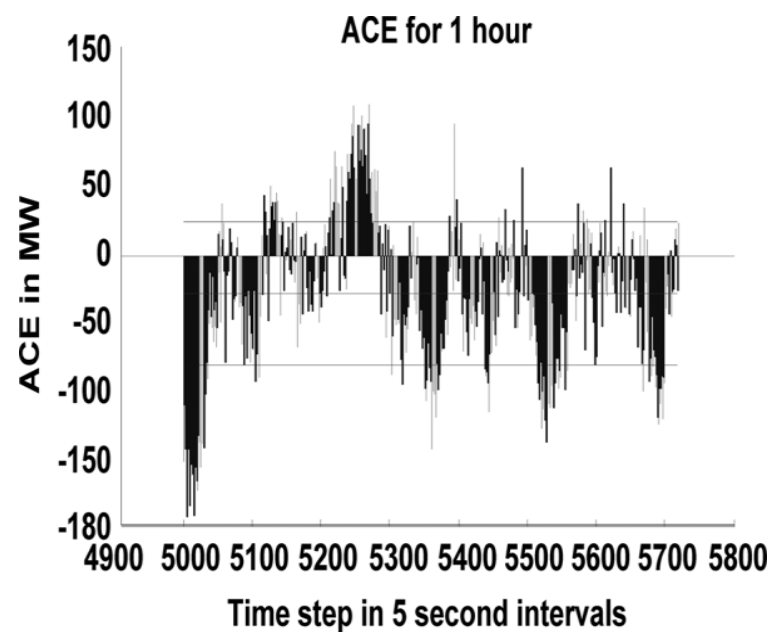

Fig. 2 ACE data with mean and standard deviation

When ACE occurs changes in daily load pick up/drop or loss of INGs. Through the rotor kinetic energy stored and the controller of governor detect the change in the ACE by change in constant speed. The control of governor action take place than turbine valves are opens to the power grid at a constant speed and at a new steady-state. However, since the set of inputs are reference point such as the incoming steam demand with corresponds to input power demand, so that does not change the constant speed drops, which results in a drop in the grid-operating frequency. At the certain instant, when the grid load is dropped, the speed and operating frequency is increased. The too much drop in constant speed can issue the grid to parallel failure because cooling fan system of steam units should be slow down, due in high temperature in motor windings of cooling fans, and this happening steam units to trip. Hence, for stable operation, the grid frequency must be accurately controlled. From APGC controls frequency in response to load changes to use the opening or closing the turbine valves However, the primary energy source as boiler overrides the opening of turbine vales as shown in Fig. 1. However, the primary energy source (boiler) overrides the opening of turbine vales if the steam pressure drops below a secure limit.

To implements the above objectives, all APGC software is used on single base unity control system. For expression (1), the desired generation at time instant $\mathrm{k}$ which is normally observed every4-10s is given by

$$
\mathrm{P}_{\mathrm{D}}^{\mathrm{i}}(\mathrm{k})=\mathrm{P}_{\mathrm{E}}^{\mathrm{i}}(\mathrm{k})+\mathrm{P}_{\mathrm{R}}^{\mathrm{i}}(\mathrm{k})+\mathrm{P}_{\mathrm{EA}}^{\mathrm{i}}(\mathrm{k})
$$

Where $\operatorname{PiE}(\mathrm{k}), \operatorname{PiR}(\mathrm{k}), \operatorname{PiEA}(\mathrm{k})$ are the economic, regulating, and emergency source assist components of desired generation for unit i respectively. $\mathrm{k}$ is the time step in seconds. However, the time step of EDC is kk which is 5-15 min. The desired generation of unit $i$ is calculated using equation from 2-4 respectively

$$
\begin{aligned}
\mathrm{P}_{\mathrm{E}}^{\mathrm{i}}(\mathrm{k}) & =\mathrm{EPF}^{\mathrm{i}}(\mathrm{kk})+\Delta \mathrm{P}_{\mathrm{T}}(\mathrm{k})+\mathrm{P}_{\mathrm{EB}}^{\mathrm{i}}(\mathrm{kk}) \\
\mathrm{P}_{\mathrm{R}}^{\mathrm{i}}(\mathrm{k}) & =\mathrm{G} \times \mathrm{RF}^{\mathrm{i}} \times \operatorname{ACE}(\mathrm{k}) \\
\mathrm{P}_{\mathrm{EA}}^{\mathrm{i}}(\mathrm{k}) & =A F^{\mathrm{i}} \times \operatorname{ACE}(\mathrm{k})
\end{aligned}
$$

$\mathrm{kk}$ is the time step of (EDC) in minutes at which the economic participation factors of EPFi and economic base points PiEB are computed. The values of EPFi(kk) and PiEB used in the calculation of PiE are those calculated by the most advanced execution of the EDC. AFi, RFi, are the emergency factor and regulating factor for unit $\mathrm{i}$, respectively. In expression (3), $\mathrm{G}$ is the regulating system gain factor, $\mathrm{AF}, \mathrm{RF}$, and $G$ are tuned in the field for proper unit control. In expression(2), is the change in total unit economic desired generation at time step $\Delta \mathrm{P}_{\mathrm{T}}(\mathrm{k})$ (in seconds)based on the most advances execution of the EDC function at time instant $\mathrm{kk}$ (in minutes). The term $\Delta \mathrm{P}_{\mathrm{T}}(\mathrm{k})$ is calculated using 


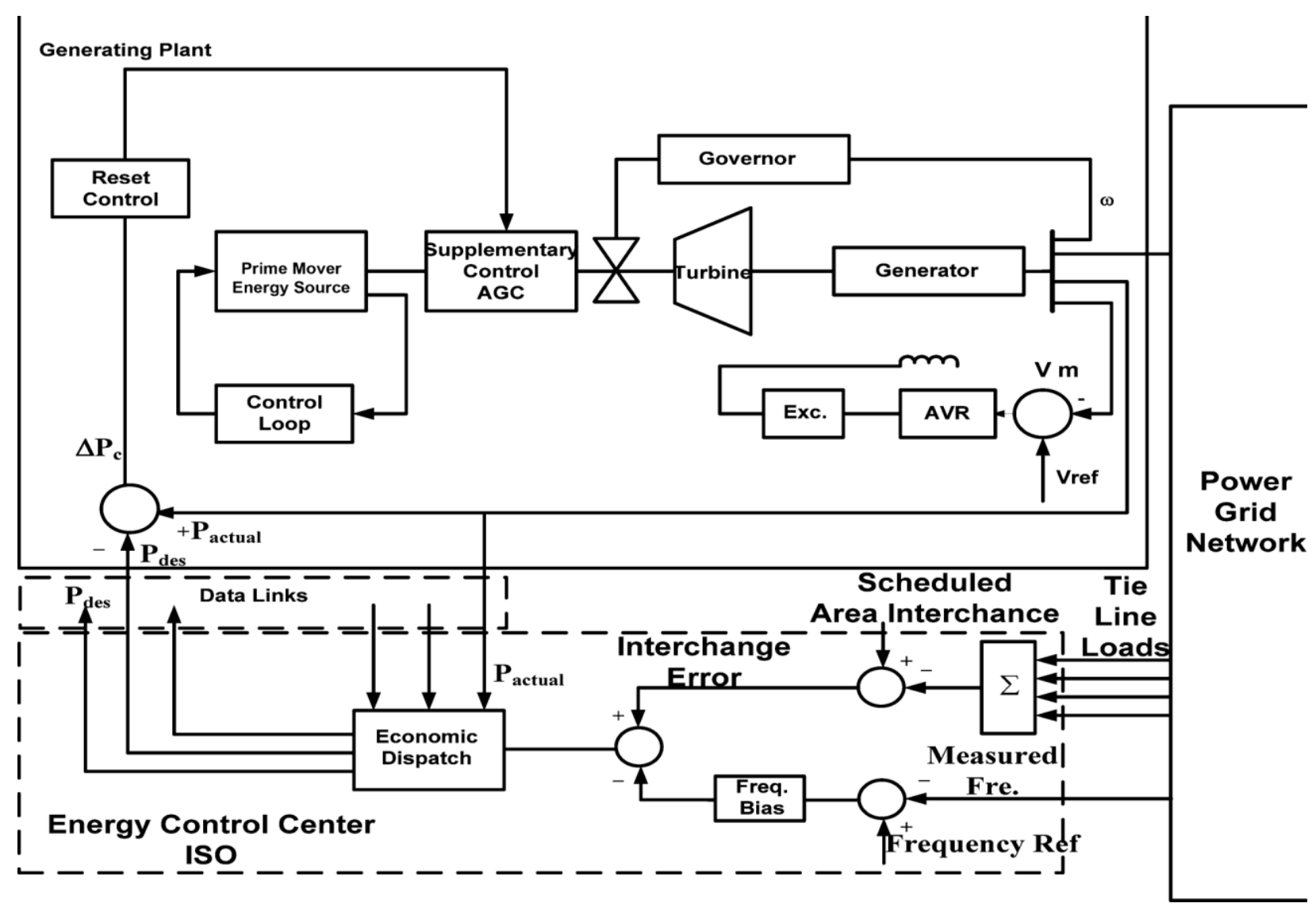

Fig.1 Current automatic generation control (A PGC). AVR: Automatic voltage regulator; Vref: AVR reference voltage; VM: measured voltage; Exc: Excitation; Factual: generated power unit i; P desire: desired power output unit i.

$$
\Delta \mathrm{P}_{\mathrm{T}}(\mathrm{k})=\sum_{\mathrm{i}=1}^{\mathrm{N}} \mathrm{P}_{\mathrm{A}}^{\mathrm{i}}(\mathrm{k})+\mathrm{ACE}(\mathrm{k})-\sum_{\mathrm{i}=1}^{\mathrm{N}} \mathrm{P}_{\mathrm{EB}}^{\mathrm{i}}(\mathrm{kk})
$$

Where PiAis the actual generation of unit $\mathrm{i}$ at time $\mathrm{k}$, ACEis the area control error at time instant $\mathrm{k}$, is the economic base point for unit $\mathrm{i}$ calculated by the most advances execution of the EDC at time $\mathrm{kk}$, and $\mathrm{N}$ is the number of units operating in the APGC control system Nearly all of the APGC software systems have some kind of clean for avoiding the noise part of ACE which cannot be controlled [2]-[8].

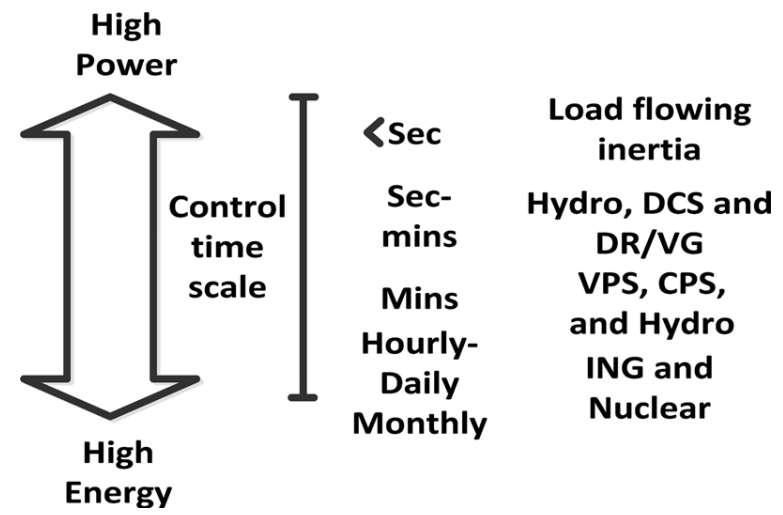

Fig 3 Control time scale of power grid assets systems

It can be the EDC and ACE both control the task ofmatching the area for power generation to power consumed area load, such that the resultant of tie-line exchange and frequency of the area are their programmed values. Both of the control functions are handled by variation governor motors to demanding of MW load due to the adjusting of MW generated system ( in Fig. 1). The high selection rate of the area load provides a quite accurate direction of the changing load demand which allows the tie-line bias method to follow the load. 


\section{STRUCTURE OF APGC FOR SMART ECTRICAL POWER GRIDS}

The steam units as operated presently, have very limited changeable operations. The ACE and EDC control functions are handled by controlling methods under APGC by to be adjustment of the MW demand of the electrical grid load to MW generated system.. If the system load is changes rapidly i.e increasing or decreasing, or if intermittency occurs in INGs due to the of changing wind-patterns, or cloud formation, the situation is appreciably different. In a smart grid, ING assets and electric vehicles, loads introduce a major obstruction in determining satisfactory of APGC control [7]-[10]. Under this situation, a new important set of control system must be used and also a new set of economic factors is needed. Since INGs are nonfarm resources, gas-fired units are used to moderate sudden outage of INGs. Moreover, the cost of gas-fired units is costly spinning reserves. Therefore, DCS and demand response (DR) are necessary to control the intermittency of ING assets. The average of DR can be used as agent of VGs of various sizes to control the grid, when ACE is very high (see Fig. 3). In order to assurance of the minimal carbon footprints and low cost, all providing ING assets can be used as base-load system. All nuclear units and hydal units must be used for base-load system because they cannot contribute in regulation due to protection purposed. In the proposed control structure (see Fig. 4), VPS, , and CPS units can be used for lowfrequency load fluctuations based on a one-step-ahead load target. A load aim with time horizon of 5-15 min can facilitate control of these systems to follow an assigned targeted load. Note that hydro units, depending on dynamic response, may be used in both low- and high-frequency load controls. The combined use of high- frequency load control. The combined use of hydro, DCS, and DR/VG assets can hold a high level of diffusion of ING assets. The proposed APGC control (see Fig. 4) can follow the low frequency dynamic load trends using a one-step-ahead load for CPS units and optimally for VPS units. This in turn can be lead to a reduction of ACE at the sampling rate of the economic dispatch. The ACE reduction can reduce the control actions by the APGC controller, which in turn eliminates the unnecessary pulsing of the steam regulating units. The high value of ACE is due to high frequency load fluctuations or sudden decrease in wind speed (generation). The control of the high value of ACE is achieve by using DCS and DR/VG grid assets (see Fig. 3).

\section{CYBER-ARCHITECTURE ELECTRICAL GRIDS}

SMART

Fig:.5 shows that, the proposed cyber-architecture to facilitate the goals of a smart grid with large numbers of ING system in the form of PV, wind, tidal, and micro grids in distribution systems. To confutes VGs of different sizes for an ISO, the proposed cyber-architecture should be developed for a smart electrical grid that consists of large number of nodes, with sensors for measuring the grid states (bus bar voltages) and phase or angle measurement units (PMU)[10]

Optimal resource distribution decisions are to be made based on output signals and inputs signals from the sensor nodes. Hence. the smart electrical power grid control structure, fully depends on the availability of a reliable moving forgathering sensor information and disseminating control information. Fig. 5 shows, a server fusion node (SFN) that can be used to observe and control at various locations in the grid for collection data and aggregation, pre filtering, and post filtering. From the smart meters are the points of communication with end energy user/provider (E/P), where residential, industrial, and commercial consumers are located. At sub transmission level, larger energy providers, such as independent power producers and large serious power sites, are located. At the transmission level, tie-line power (TPL) to other related power grids is metered and data are sent to the ISO control center. The VG units can be construing from a big number DRs in each zone through smart meters. DRs most be aggregate to a sum load in a few demands under the control of command for APGC software. Then, VGs can be controlling through the APGC when ACE exceeds its limited value. The design of a virtual-architecture faces a large number of challenges, as well as the possibility of incomplete information flow due to message losses and inhibited computation resources. If wireless networks, a highly popular choice of message system are used, the messages are transmitted in a multi hop fashion from the source to the intention via a number of fusion nodes, where resource allocate decisions are made. While there have been a great deal of work, taking place the design of control algorithms used for wireless networks, the smart grid applications is require several special cases, such as the need to collected information from a large number of sensor nodes moreover in real-time, stringent delay and reliability requirements data. for APGC. Moreover, the delay in aggregating a number of DRs may be controlled in distribution systems for low loss of data. The virtual structure must have a tree-like structure of a power grid, with high density in some places such as the distribution systems; this is the backbone of a network for APGC is likely to be comprised of a fiber-optic transmission-line access toward sensors nodes at detached locations. Moreover, a wireless network can be used in residential distributions. 


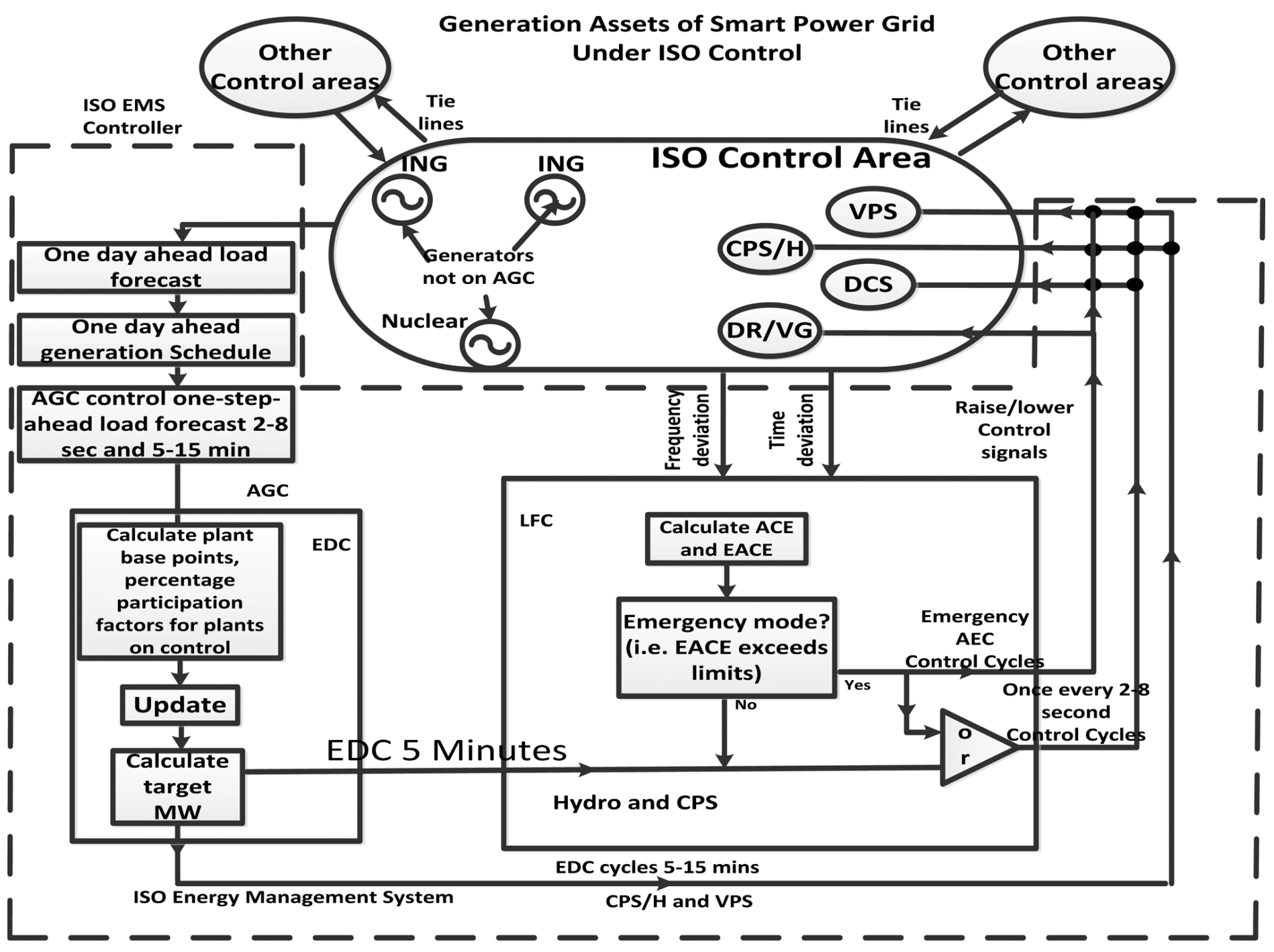

EACE: Emergency ACE; ACE: Area Control Error; CPS/H: Steam or Hydro Units; VPS: Variable Pressure Steam Units DR/VG: Virtual Generator- Demand Response; DCS: Distributed Community Storage Units; ING: Intermittent Non-Dispatchable Distributed Generator Units

Fig 4 The proposed APGC control structure for electrical mart power grid.

\section{DECISION AND CONTROL}

\subsection{One-Step ahead Load Model System}

The discussion taken for above case, it can be obvious, from the outset the control plan should identify the load changes due to high-frequency fluctuations, which are within low-frequency fluctuations and dynamic response of APGC resources.

APGC must adopted decision and control plans to managed with the low and high frequency load fluctuations, through help of modeling the load dynamic responses using the one-stepahead load model system, both high- and low-frequency load fluctuations can be controlled by carefully selection of APGC resources The idea behind this methodology is based on system identification [11]using a sample of observations $\mathrm{Y}(\mathrm{k})$ and identifying the basic process of model system and its parameters. The load monitoring(observing)sequence corresponds to stochastic processes [12] and is produced by an autoregressive moving average (ARMA) model given below

$$
\begin{aligned}
Y(k)=\sum_{j=1}^{n} a_{j}(k) & Y(k-j) \\
& +\sum_{j=1}^{m} a_{n+j}(k) \cdot W(k-j)+W(k) . .
\end{aligned}
$$


This model can be expressed in compact form as (7)

$$
\begin{aligned}
\mathrm{Y}(\mathrm{k})= & \mathrm{a}^{\mathrm{T}}(\mathrm{k}) \mathrm{Z}(\mathrm{k}-1)+\mathrm{W}(\mathrm{k}) \\
\text { where }^{\mathrm{T}}(\mathrm{k})= & {\left[\mathrm{a}_{1}(\mathrm{k}), \ldots, \mathrm{a}_{\mathrm{n}+\mathrm{m}}(\mathrm{k})\right] } \\
\mathrm{Z}^{\mathrm{T}}(\mathrm{k})= & {\left[\mathrm{Z}_{1}(\mathrm{k}), \ldots, \mathrm{Z}_{\mathrm{n}}(\mathrm{k}) ; \mathrm{Z}_{\mathrm{n}+1}(\mathrm{k}), \ldots \mathrm{Z}_{\mathrm{n}+\mathrm{m}}(\mathrm{k})\right] } \\
\mathrm{Z}^{\mathrm{T}}(\mathrm{k})= & {[\mathrm{Y}(\mathrm{k}-1), \ldots, \mathrm{Y}(\mathrm{k}-\mathrm{n}) ; \mathrm{W}(\mathrm{k}-1), \ldots,} \\
& \mathrm{W}(\mathrm{k}-\mathrm{m}+1)] \\
\overline{\mathrm{W}}(\mathrm{k}+1)= & \mathrm{Y}(\mathrm{k}+1)-\hat{a}^{\mathrm{T}}(\mathrm{k}+1) \cdot \mathrm{Z}(\mathrm{k}) .
\end{aligned}
$$

The residuals error $\mathrm{W}(\mathrm{k}+1)$ can be used to estimated and constructed the ARMA model, if the past residual error has steady dynamics. The one-step-ahead predictor model and error are given as

$$
\begin{aligned}
\hat{\mathrm{Y}}(\mathrm{k}+1) & =\hat{\mathrm{a}}^{\mathrm{T}}(\mathrm{k}) \cdot \mathrm{Z}(\mathrm{k}) \\
\mathrm{e}(\mathrm{k}+1) & =\mathrm{Y}(\mathrm{k}+1)-\hat{\mathrm{Y}}(\mathrm{k}+1)
\end{aligned}
$$

Where $\mathrm{W}(\mathrm{k})$ is an immeasurable disturbance and is white with zero mean, when a suitable ARMA model is identified for the process. The one-step-ahead predictor of the load sequence is given below in Fig. 6.

$$
\begin{aligned}
\mathrm{Y}(\mathrm{k})=0.0014 \mathrm{Y}(\mathrm{k}-1)+ & 0.62 \mathrm{Y}(\mathrm{k}-2) \\
+ & 0.376 \mathrm{~W}(\mathrm{k}-1)+\mathrm{W}(\mathrm{k}) .
\end{aligned}
$$

The parameter vector is $\mathrm{a}^{\mathrm{T}}$ identified from observation as $\hat{a}^{T}$ [13]. I submit the proposed method can be used to model the load sequence base on the last large samples of observations rates. Anther, one-step-ahead load model can be the after a few observations, imprison the load dynamic responses dazzling and identifying both high and lowfrequency fluctuation loads.

The ACE fluctuation is a feedback signal that identifies the of ING generators. Note that during any sudden loss occur of wind, load controlled by the energy consumers remains the same. Whenever, the unbalance between generation and load is measured trough high value of ACE.

The ACE value can be used as a feedback signal to select suitable system to control the system frequency as described below.

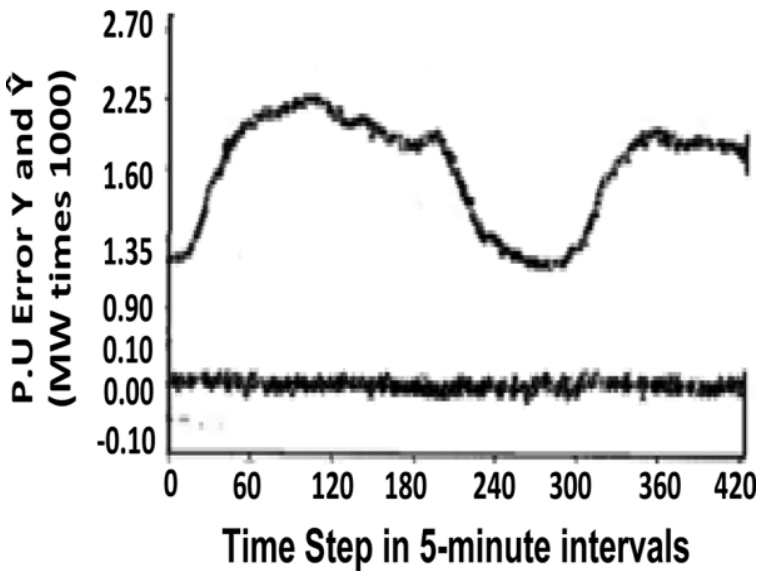

Fig 6 The one-step-ahead load model predictor [13] 


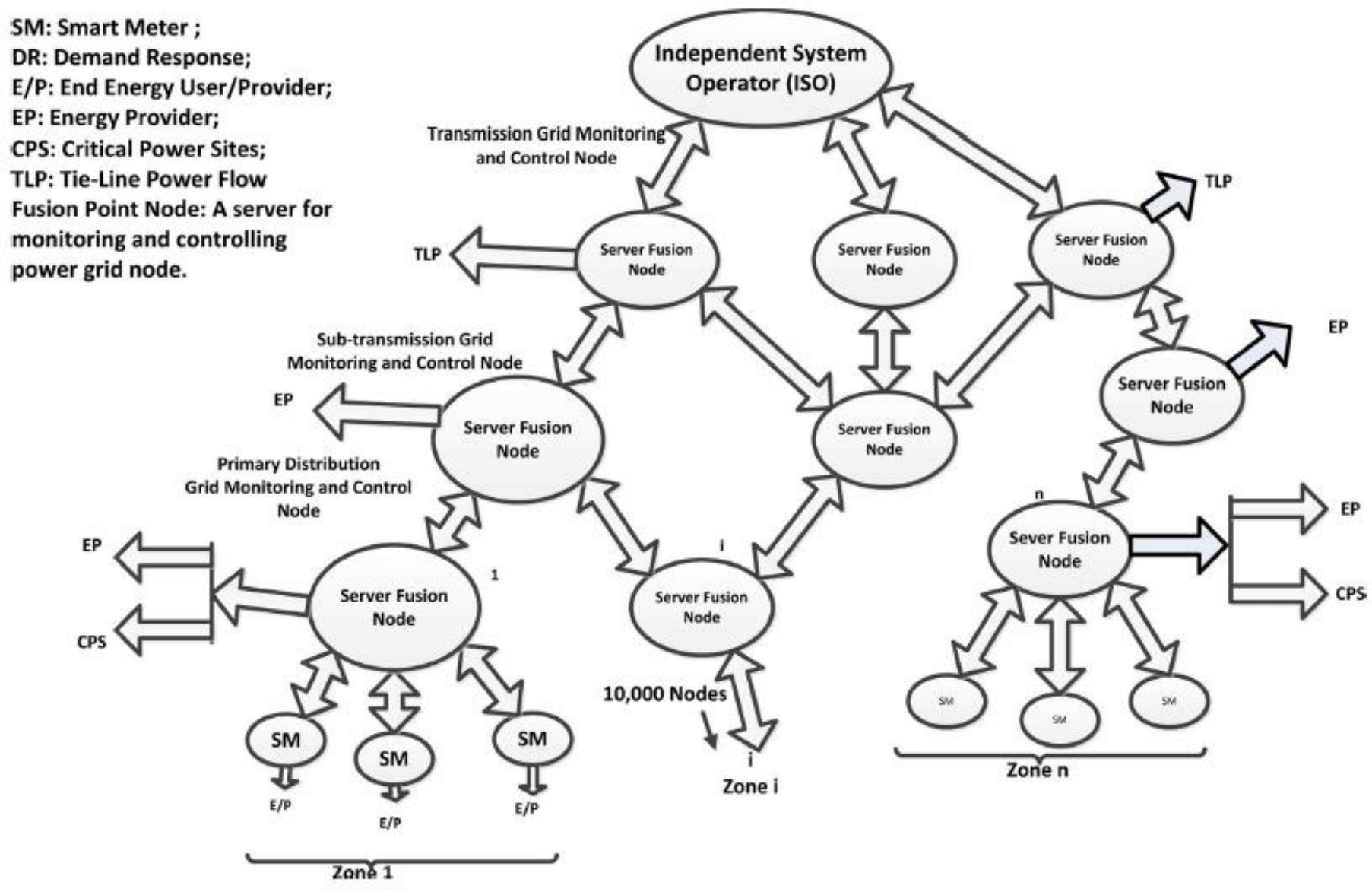

Fig 5 The proposed cyber architecture

\subsection{VGAND.DCS Units Control System}

The final decision taken place, DCS and VG system is made on the basis of ACE. If ACE is extremely negative, indicating the deficiency in energy balance (a drop in frequency), the APGC controller identifies, this state as an emergency state (see Fig. 4.).The VG system can be used for an instant drop of load and maintained the energy balance, thus, restored the frequency to a normal state from the ACE method, presented in Fig. 2, that the need for VG system can be used for a very short time, in the order of few seconds to a few minutes, unless the grid remains in the emergency state. The alert state occurs when ACE has a to determined dynamic trend toward the emergency state. For the alert state, DCS system should be used to maintain the energy balance in a few seconds. The response of a DCS-inverter is shown in Fig. 7. I have studied the dynamic response of the DCS-inverter[8].

\subsection{Control of CPS Units}

The on-line system one-step load model can used to assigned a maximum load to the units under CPS control. The CPS units comes under the boiler control system and have been multi face ted thermal processes. The models of CPS units for APGC system do not have been developed because CPS units has a limited regulating capabilities, the APGC software controls ,the CPS units from the turbine valves. Valve point of CPS units reduces the throttle loss and wear of the valves. The one-stepahead, load can be used for valve point for loading of the CPS units. Control of this units for APGC documented in [4]. 

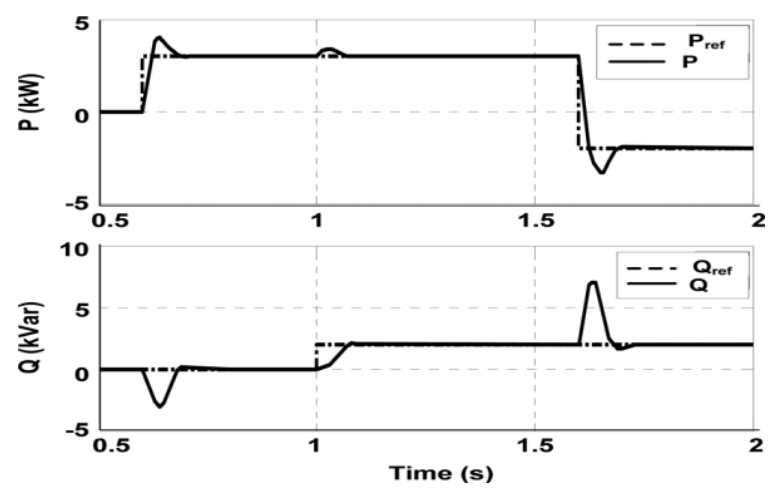

Fig 7P.Q, regulation of a laboratory microgrid [8].

\subsection{VPS Control Units}

The VPS units can be accurately controlled by APGC by using dynamic response of VPS units. In [14], the gross drum model type boiler was developed. In this paper, this model is used to for accurately control of VPS units, to maintained demonstrated of model. The control problem is calculated by using the optimal control theory by Bryson and Ho [15] and implemented in Matlab. The discrete state-space model of the VPS model is given in (10).

$$
\mathrm{X}(\mathrm{k}+1)=\mathrm{A} \cdot \mathrm{X}(\mathrm{k})+\mathrm{B} \cdot \mathrm{U}(\mathrm{k}), \mathrm{k}=0,1, \ldots
$$

Where the variable $\mathrm{X}$ is the drum pressure and $\mathrm{U}$ is the input control of fuel flow, the control valve setting, and the feed water, respectively.

The vector difference (10) indicates the dynamic performance of the VPS unit, where $\mathrm{X}(\mathrm{k}+1)$ belongs ton dimensional space and is the state variable at time $\mathrm{k} ; \mathrm{U}(\mathrm{k})$ belongs to $\mathrm{m}$ dimensional space and is the input at time $\mathrm{k}$; $\mathrm{A}$ is $\mathrm{n} \mathrm{xn}$; and $\mathrm{B}$ is $n \times m$ matrix. The MW output of the VPS unit can be expressed as a function of state variables, and the input variables at any time instant $\mathrm{k}$. That is,

$$
\mathrm{P}(\mathrm{k})=\mathrm{F}(\mathrm{X}, \mathrm{U}, \mathrm{k})
$$

Where $\mathrm{P}(\mathrm{t})$, is the MW output at time instant $\mathrm{k}$.

$$
\begin{aligned}
\int_{t_{0}}^{t_{f}} P(t) & =\frac{P_{G}\left(t_{0}\right)+A C E_{0}+P_{f}}{2} T \\
\sum_{k=0}^{N-1} P(k) t & =\frac{P_{G}\left(k_{0}\right)+A C E_{0}+P_{f}}{2} T, N=\frac{T}{\Delta t}
\end{aligned}
$$

Where $\mathrm{T}$ is the period of control and $\Delta \mathrm{t}$ is the subinterval of control represented by $\mathrm{k}$. The energy delivered to the grid is at the same time as presented by [15].
The control problem is formulated as a linear separate control problem for small load instability and the constraint are as follows:

a) Final time of control is fixed

b) Initial and terminal boundary values are given

$$
\mathrm{X}(0)=\mathrm{X}_{0} \quad \text { and } \quad \mathrm{X}(\mathrm{N})=\mathrm{X}(\mathrm{T})
$$

c) The control variables and the state variables must satisfy a magnitude constraint

$$
\begin{aligned}
& \mathrm{X}_{\min } \leq \mathrm{X}(\mathrm{k}) \leq \mathrm{X}_{\max } \quad \text { and } \\
& \mathrm{U}_{\min } \leq \mathrm{U}(\mathrm{k}) \leq \mathrm{U}_{\max } .
\end{aligned}
$$

d) The rate of change of the state variables must satisfy a magnitude constraint

$$
|X(k+1)-X(k)| \leq X_{\text {rate }} .
$$

e) The rate of change of the state variables must be zero atk=N: at the end of control cycle, i.e., the system must reach their a steady state at the final time

$$
\mathrm{X}(\mathrm{N}-1)-\mathrm{X}(\mathrm{N})=0 .
$$

The problem is to find the optimizing control sequence

$\mathrm{U}=(\mathrm{U} 0, \mathrm{U} 1 \ldots \mathrm{U} \mathrm{N}-1)$ and the corresponding route

$\mathrm{X}=(\mathrm{X} 0, \mathrm{X} 1 \ldots . \mathrm{X}(\mathrm{N}))$ and subject to conditions a) through e $)$,

While minimizing the performance index given by (14):

$$
\mathrm{J}(\mathrm{U})=\sum_{\mathrm{k}=0}^{\mathrm{N}-1} \mathrm{~d}^{\mathrm{T}} \mathrm{U}(\mathrm{k})
$$

Where $\mathrm{d}$ is a weighing vector on control actions. The accurately dynamic generation response control is proved, when the VPS units are controlled by the above constraints. Equation (13) indicates, power consumed by the load and power supplied to the system must be equal. Therefore, the power balance enables APGC to control the system frequency and the planned exchange of power with the nearest grids. The control constraints require that the VPS unit to reached a constant state at the final control stage, this will be happened in about 2-3times of the constant of the VPS unit. This is a very important if VPS unit is to be steered again to another target MW. The rest of the situation and constraints are used by practical considerations. For example, the rate of change of the 
state variables is constrained, which in turn limits the rate at which the load can be picked up or dropped. The boiler-turbine model developed by Astrom and Eklund [14] with a maximum output of 160MWis used to demonstrate the control method.Fig. 8
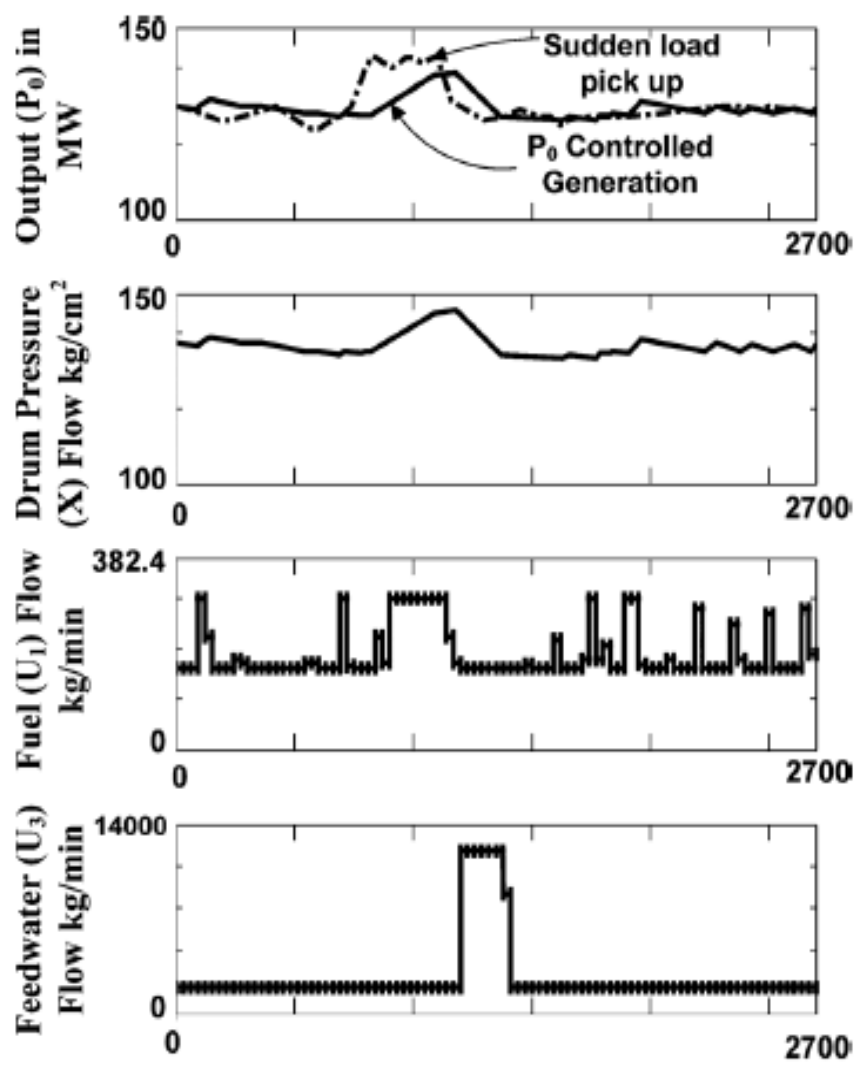

Time in sec

Fig 8 Optimal dynamic generation control of a VPS

Fig:8shows eight periods of control cycles (i.e one Hour) the variable pressure operations with turbine valves, U2 set at $95 \%$. Also shown are the corresponding fuel flow U1 and feed water flow U2, according condition (police). The proposed variable pressure operation is based on a one-step-ahead, load to reached maximum valves for a VPS unit. Therefore, for this type operation, an online load modeling method with observing intervals based on dynamic VPS units must be developed. Since the important boiler dynamics is used in the control problem formulated, the temperature changes within the turbine when the throttling losses must be deleted. Than automatically reduces the thermal weakness and increases the efficiency of operation.

\section{CONCLUSIONS}

The proposed work, APGC control structure can contained ING penetrations by identified the load fluctuations is easily measured by ACE method, high and low frequency system. The levels of INGs in the smart grid must corresponding to
DCS and VG systems under APGC control system in the order to as per as possible to minimum of the costly installation of gas-fired units for spinning reserves. The CPS units can also be controlled to follow of steam or objective load with a longer control of time cycle to keep the steam pressure within a not dangerous limit and realize valve-point loadings. The given proposed method of control minimum both the steady state and dynamic cost of units. During the normal operation conditions of the electrical power grids, the VPS and CPS units can be used for controlled as changeable units for low frequency load fluctuations with hydro, wind, DCS, and DR/VG as complimentary agents for corresponding for high-frequency load fluctuations. During the alert state, the EDC is suspended and DCS system are dedicated to regulation. In the case of emergency state, DR/VG systems are dedicated to stabilizing the grid and controlling the system frequency. As penetration of INGs increase, the DCS and VG units must be installed. The proposed control structure mitigates the INGs' control problems in the smart electrical power grids. However, the development of APGC simulation based, on this paper needs further research. The research problems are as follows: i) A cyber-structure power grid system that can observe the state of power grid; ii) Online unpleasant dynamic models of boilers. iii) A smart power grid APGC simulator for operator training system.

\section{REFERENCES}

[1]. J. J. Conti et al., "Annual energy outlook 2011 with projections to 2035," U.S. Energy Information Administration, 2011.

[2]. N. Jaleeli, L. S. VanSlyck, M. M. Yao, R. R. Shoults, and R. Kelm, "Discussion of AGC logic based on NERC's new control performance standard and disturbance control standard," IEEE Trans. Power Syst., vol. 15, no. 4, pp. 14551456, Nov. 2000.

[3]. A. J. Wood and B. F. Wollenberg, Power Generation Operation and Control, 2nd ed. New York: Wiley, 1996.

[4]. P. Kundur, Power System Stability and Control. Palo Alto, CA: Mc-Graw-Hill, 1994.

[5]. V. Donde, M. A. Pai, and I. A. Hiskens, "Simulation and optimization in an AGC system after deregulation," IEEE Trans. Power Syst., vol. 16, no. 3, pp. 481-489, Aug. 2001.

[6]. J. Kumar, K. Ng, and G. Shelbe, "AGC simulator for pricebased operation part 1: a model," IEEE Trans. Power Syst., vol. 12, no. 2, pp. 527-532, May 1997.

[7]. A. Keyhani, M. N. Marwali, and M. Dai, Integration of Green and Renewable Energy in Electric Power Systems. Hoboken, NJ: Wiley, 2010.

[8]. A. Keyhani, Design of Smart Grid Renewable Energy Systems. Hoboken, NJ: Wiley, 2011.

[9]. A. Nourai and C. Schafer, "Changing the electricity game," IEEE Power Energy Mag., vol. 2, no. 4, pp. 42-47, 2009.

[10]. K. Moslehi and R. Kumar, "Vision of a self-healing power grid,” ABB Rev., pp. 21-25, Apr. 2006. 
[11]. L. Ljung, "Perspectives on system identification," in Annual Reviews in Control. : Elsevier, 2010.

[12]. A. Keyhani, "Stochastic load modeling and optimal dynamic generation control," Ph.D. dissertation, School of Electrical Engineering, Purdue Univ., West Lafayette, IN, 1975.

[13]. A. Keyhani and A. H. El-Abiad, "One step-ahead load forecasting for on-line applications," presented at the IEEEWinter Power Meet., New York, 1975, Paper CP 221PWR.

[14]. K. J. Astrom and K. Eklund, "A simplified non-linear model of a drum boiler-turbine unit," Int. J. Control, vol. 16, no. $1,1972$.

[15]. A. E. Bryson and Y. C. Ho, Applied Optimal Control: Optimization, Estimation, and Control. Waltham, MA:

Blaisdell, 1969, p. 481 